\title{
PENGADAAN PROGRAM LITERASI PADA PERPUSTAKAAN SMPN $X$ KABUPATEN BANYUWANGI
}

\author{
Lucky Kurniawan ${ }^{1}$ \\ ${ }^{1}$ Mahasiswa, Ilmu Perpustakaan dan Sains Informasi, Universitas Negeri Malang
}

\begin{abstract}
ABSTRAK
Tujuan dari penelitian untuk mengetahui gambaran program literasi yang ada Di Perpustakaan SMPN $X$ Kabupaten Banyuwangi saat ini, sebagai bahan pertimbangan untuk membuat dan mengadakan Program Literasi Perpustakaan. Penelitian ini menggunakan pendekatan kualitatif dengan metode studi kasus, dengan teknik pengumpulan data melalui wawancara terhadap pustakawan (online via Whatsapp). Hasil penelitian ini menunjukkan 1) Perpustakaan di kelola oleh 2 pustakawan; 2) Belum adanya program literasi yang pure dari perpustakaan;3) Program literasi satu-satunya adalah program GLS yang berupa membaca 15 menit sebelum kegiatan belajar mengajar (PBM) di mulai;4) Program Perpustakaan hingga saat ini masih sebatas kerjasama dengan para guru, untuk mengadakan PBM di ruang perpustakaan. Dari hasil tersebut peneliti membahas tentang Program Literasi yang akan diadakan dengan jadwal Harian, Mingguan, Bulanan, dan Per Semester. Peneliti juga memberikan gambaran akan hambatan-hambatan yang menghalangi kemampuan berliterasi secara umum yang dapat mempengaruhi kemampuan berliterasi siswa.
\end{abstract}

Kata kunci: Program Literasi, Perpustakaan Sekolah, Sekolah Menengah Pertama

\begin{abstract}
The purpose of the research is to find out the description of the literacy program in the Library of the SMPN X Banyuwangi Regency, as a material consideration for making and holding a Library Literacy Program. This study uses a qualitative approach with a case study method, with data collection techniques through interviews with librarians (online via Whatsapp). The results of this study indicate 1) The library is managed by 2 librarians; 2) There is no pure literacy program from the library; 3) The only literacy program is the GLS program in the form of reading 15 minutes before teaching and learning activities (PBM) starts; 4) The Library Program is still limited to collaboration with teachers, to hold PBM in the library room. From these results, the researchers discussed the Literacy Program which will be held with a schedule of Daily, Weekly, Monthly, and Per Semester. Researchers also provide an overview of the obstacles that hinder the ability of general literacy which can affect the ability of students to be illiterate.
\end{abstract}

Keywords: Literacy Program, School Library, Junior High School 


\section{PENDAHULUAN}

Tingkat kemajuan suatu negara dapat dinilai dari kualitas pendidikan warganya. Pendidikan yang baik dalam suatu negara mempengaruhi kualitas dari tingkah laku dan cara pikir masyarakatnya. Sesuai dengan yang tercantum pada undangundang Sistem Pendidikan Nasional No. 20 tahun 2003, sekolah sebagai lembaga pendidikan formal bertujuan mengembangkan potensi berupa kepribadian, kecerdasan, ahlak mulia serta keterampilan-keterampilan lainnya yang berguna untuk dirinya, masyrarakat, bangsa, dan negara (Departemen Pendidikan Nasional, 2003).

Berbicara tentang pendidikan, terdapat faktor-faktor yang berperan penting dalam membangun pendidikan. Salah satu faktor penting tersebut adalah keberhasilan perpustakaan sebagai fasilitas penunjang di sekolah. Diharapkan perpustakaan sekolah dapat menumbuhkan dan mengembangkan literasi, agar siswa dapat memanfaatkan informasi dan pengetahuannya secara maksimal, seperti dinegara-negara maju yang budaya bacanya tinggi, contohnya Negara Inggris, Selandia baru, Kanada, Jerman, dan Amerika serikat (Koroh, 2015).
Maka dari itu sangat perlu untuk mengembangkan perpustakaan sebagai penopang literasi warga sekolahnya. Perpustakaan harus berperan dalam membangun sikap para siswanya untuk sadar kapan membutuhkan informasi, mengapa membutuhkan, kemana harus mencari, bagaimana cara untuk mengevaluasi, menggunakan, dan mengkomunikasikan informasi tersebut (Sudarsono, 2009). Mengembangkan perpustakaan tak hanya melulu tentang koleksi maupun fasilitasnya. Hal penting lainnya yaitu adalah program literasi perpustakaannya. Dengan latar belakang tersebut, peneliti tertarik untuk membuat sebuah program literasi perpustakaan dengan mengambil subjek penelitian di SMPN $X$ Kabupaten Banyuwangi, karena untuk saat ini masih belum terdapat program literasi yang pure dari Perpustakaan sendiri.

Peneliti memilih Sekolah Menegah Pertama karena pada tingkat sekolah menengah perlu diperhatikan betul, sebab pada jenjang pendidikan ini cukup krusial menurut Napitupulu (2011), sebab pada jenjang pendidikan menengah mereka mendapatkan pendidikan tentang pengetahuan, sikap dan ketrampilan sebagai bekal untuk tingkat selanjutnya (Napitupulu 2011). Kemerosotan 
pendidikan di tingkat menengah ini dapat di lihat pada penelitian yang dilakukan oleh Organisasi untuk Kerja Sama dan Pembangunan Ekonomi $\quad(O E C D-$ Organization for Economic Cooperation and Development) dalam Programme for International Student Assessment (PISA), dimana pada tahun 2009 menduduki peringkat ke-57 dan di tahun 2012 turun di peringkat ke-65 (Panduan Gerakan Literasi Sekolah di Sekolah Menengah Pertama, 2016).

\section{METODE PENELITIAN}

Penelitian ini menggunakan pendekatan kualitatif dengan metode studi kasus. Analisis dilakukan secara mendalam mengenai Program Literasi yang ada di Perpustakaan SMPN $X$ Kabupaten Banyuwangi, dengan teknik pengumpulan data melalui wawancara terhadap pustakawan (online via Whatsapp).

\section{PEMBAHASAN}

\section{A. Gambaran Program Literasi Di SMPN $X$ Kabupaten Banyuwangi}

Perpustakaan SMPN $X$ terletak di tengah gedung-gedung pusat pembelajaran. Mudah dijangkau oleh siswa karena letak yang dekat dengan kelas para siswa, namun saat ini terdapat rencana pemindahan ke gedung baru yang terdapat pada pojok sekolah. Data yang dapat peneliti terima dari hasil wawancara secara daring (online) terkait program literasi perpustakaan melalui aplikasi Whatsapp berupa :

1) Perpustakaan di kelola oleh 2 pustakawan.

2) Belum adanya program literasi yang pure dari perpustakaan.

3) Program literasi satu-satunya adalah program GLS yang berupa membaca 15 menit sebelum kegiatan belajar mengajar (PBM) di mulai.

4) Program Perpustakaan hingga saat ini masih sebatas kerjasama dengan para guru, untuk mengadakan (PBM di ruang perpustakaan.

\section{B. Rencana Program Literasi}

\section{Perpustakaan}

\section{a. Program Harian dan Mingguan}

Dalam kegiatan ini peneliti mencoba untuk menerapkan sebuah program yang telah diterapkan oleh pemerintah Provinsi Jawa Barat, dan mencoba menerapkan pada subjek penelitian ini, yaitu Perpustakaan SMPN $X$ Kabupaten Banyuwangi. Program literasi tersebut bernama WJLRC (West Java Leader's Reading Challenge). Program ini sebenarnya adalah hasil dari para guru 
yang mengikuti pelatihan di Adelaide, Australia. Program sebenarnya yang ada di Adelaide bernama WJATP yang kemudian disesuaikan menjadi WJLRC, tidak menggunakan istilah berbahasa inggris sebab sesuai dengan MOU yang telah disetujui oleh Pemerintah Provinsi Jawa Barat dan Australia. Program tersebut berupa teknik review buku Fishbone, $Y$ chart, dan paragraf AIH (Setiyaningsih n.d.)

\section{Fishbone Diagram}

Fishbone diagram adalah sebuah teknik yang di perkenalkan oleh Doktor asal jepang yaitu Dr. Kaoru Ishikawa, disebut seperti itu karena bentuk diagram ini mirip tulang ikan. Diagram ini digunakan untuk mengidentifikasi suatu masalah dan akarnya melalui sesi brainstorming. Fishbone diagram merupakan teknik untuk membuat review dengan memasukkan data-data informasi hasil dari membaca buku ke dalam 6 bagian tulang rusuk ikan. Dari ke-6 bagian tersebut di isi berdasarkan $5 \mathrm{~W}+1 \mathrm{H}$.

- Who $=$ siapakah tokoh-tokoh dalam bacaan ?

- What= apa yang terjadi ?

- Where $=$ dimanakah tempat-tempat kejadian dalam bacaan?
- When= kapan terjadinya ?

- Why= mengapa hal itu dapat terjadi ?

- How $=$ bagaimana tindak lanjutnya/ bagaimana kejadiannya?

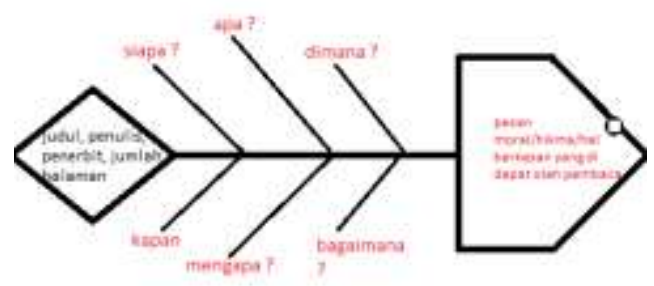

Gambar 1.

Pada bagian ekor ikan ditulis data buku yang dibaca, sedangkan pada kepala ikan ditulis catatan penting/hikmah/pesan moral berkesan yang diperoleh pembaca. Bentuk diagram ini membantu siswa dalam menstruktur pola pikir sehingga membantu pembaca dalam mengingat dan mengikat makna hasil membaca.

\section{Y-chart}

Y-chart merupakan teknik review yang digunakan pembaca dalam membantu mengembangkan dan melatih daya pikir analitis dan kritis. Dengan teknik ini pembaca dapat memetakan apa yang berkesan dari buku yang sedang atau telah dibaca, dengan memetakan menjadi 3 daerah. Pada masing-masing daerah dapat ditulis beberapa poin langsung, sesuai dengan hal-hal berkesan yang dapat ditangkap oleh panca indera pembaca. 
Ketiga daerah tersebut adalah :

1) Apa yang di lihat ?

Bagian ini pembaca menuliskan atau bisa juga menggambarkan apa yang seakan-akan ia lihat/terlihat dalam bacaannya. Semisal, pada buku Sang Pemimpi karya Andrea Hirata, pembaca mendapat gambaran atau imajinasi dari keadaan pendidikan di Tanah Belitung, keadaan pasar yang kumuh, dll. yang berkesan lalu menuliskannya.

2) Apa yang di dengar ?

Pembaca merasa ada hal menarik yang seolah-olah mereka dengar dalam bacaannya. Seperti kalimat-kalimat langsung dalam pembicaraan para tokoh di dalam bacaan. Misalnya, pada karya yang sama diatas tadi, pembaca mendengar obrolan para tokoh yang ingin bersekolah ke SMA Negeri.

3) Apa dirasakan atau dipikirkan?

Pada bagian ini pembaca meyimpulkan pesan moral apa atau hikmah apa yang diperoleh dari buku yang telah dibacanya.

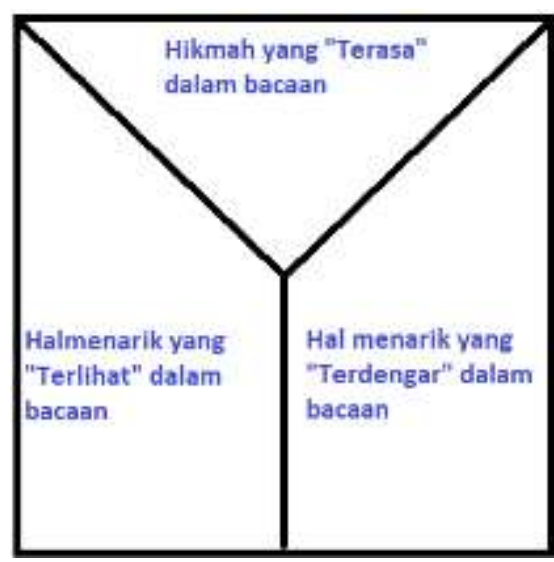

Gambar 2.

\section{Paragraf A.I.H}

Kata AIH merupakan akronim dari Alasan, Isi dari buku, dan Hikmah bacaan. Teknik ini digunakan untuk mereview hasil serta pengalaman membaca dengan model deskripsi berbentuk paragraf.

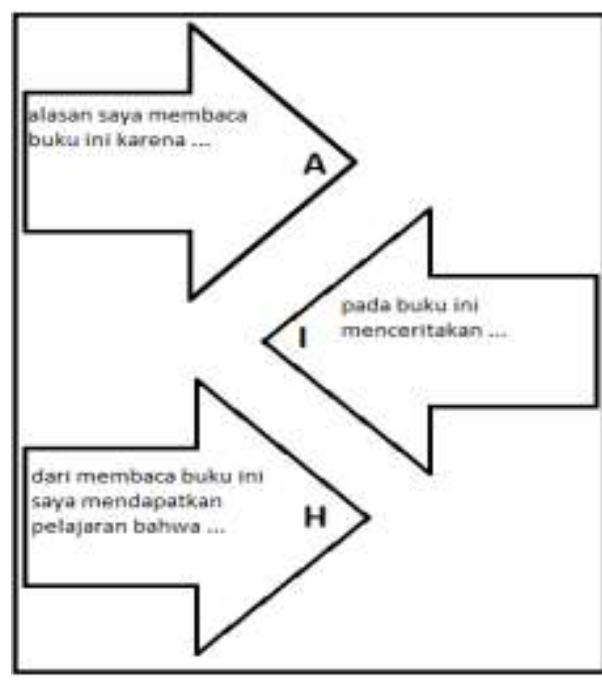

Gambar 3.

Berdasarkan teknik-teknik di atas, pihak perpustakaan akan bekerjasama dengan guru untuk menjalankan program ini. Program ini dimulai pada bulan ke-2 awal semester gasal. Bulan ke-2, 3 dan 4 
perpustakaan akan menerapkan teknik Fishbone; bulan ke-5, 6 dan 7 teknik Paragraf AIH; bulan ke-8, 9, dan 10 teknik Y-chart; dan 1 bulan berikutnya siswa diberikan kebebasan memilih teknik yang mana. Para siswa diberi tantangan untuk mereview buku sebanyak 24 buku dalam 10 bulan.

Terdapat Guru literasi sebagai pembimbing siswa dalam menjalankan program ini. Guru literasi di pilih sesuai dengan penjadwalan masing masing kelas 7,9, dan 9. Guru bisa merekomendasikan atau mempersilahkan para siswa untuk mengambil judul sesuai keinginan mereka dengan melapor terlebih dahulu kepada Guru literasi, setelah disetujui maka siswa dapat melanjutkan review bacaannya.

Siswa wajib mempresentasikan dan berdiskusi bersama pada waktu yang telah dijadwalkan. Selanjutnya Guru literasi akan melaporkan aktifitas, hasil presentasi dan diskusi dan di unggah ke website perpustakaan SMPN $X \quad$ Kabupaten Banyuwangi tiap satu minggu sekali. Pada akhir bulan penjadwalan Teknik review (akhir Semester Genap), pihak perpustakaan akan memberikan nominasi bagi siswa yang mampu menyelesaikan tantangan dan pemberian hadiah yang berupa piala maupun voucher buku.

\section{b. Program Bulanan}

\section{Cipta karya}

Menulis Artikel \& Posterisasi

Program Cipta karya yang pertama adalah lomba menulis artikel. Program ini akan diadakan setiap bulan dengan tematema tertentu. Tema bisa menyesuaikan dengan hari-hari besar maupun peringatan yang memiliki nilai penting. Program Cipta Karya yang kedua yaitu lomba Poster. Lomba poster juga hampir sama prosedur pengadaannya dengan lomba Artikel, hanya saja ada penambahan juri yang menilai.

Ketentuan dalam penyelenggaraan ini di pegang oleh perpustakaan dengan persetujuan atasan. Perpustakaan akan mengumumkan jadwal lomba beserta kriteria penulisan di mading perpustakaan dan website perpustakaan. Sistem penilaian akan di lakukan oleh para Guru Bahasa Indonesia dan Guru Kesenian.

Jika Lomba Menulis Artikel dilakukan oleh para Guru Bahasa Indonesia saja, Posterisasi di berikan tambahan juri oleh Guru Kesenian. Setelah Guru selesai melakukan penilaian, rekapitulasi nilai akan diserahkan kepada pihak Perpustakaan untuk di umumkan pada mading dan website perpustakaan. Pada akhir semester genap akan ada nominasi 
bagi siswa-siswa yang berhasil menjadi pemenang selama periode tersebut.

Sistem penyelenggaraan dan penilaian dapat dilihat pada gambar 4 dibawah :

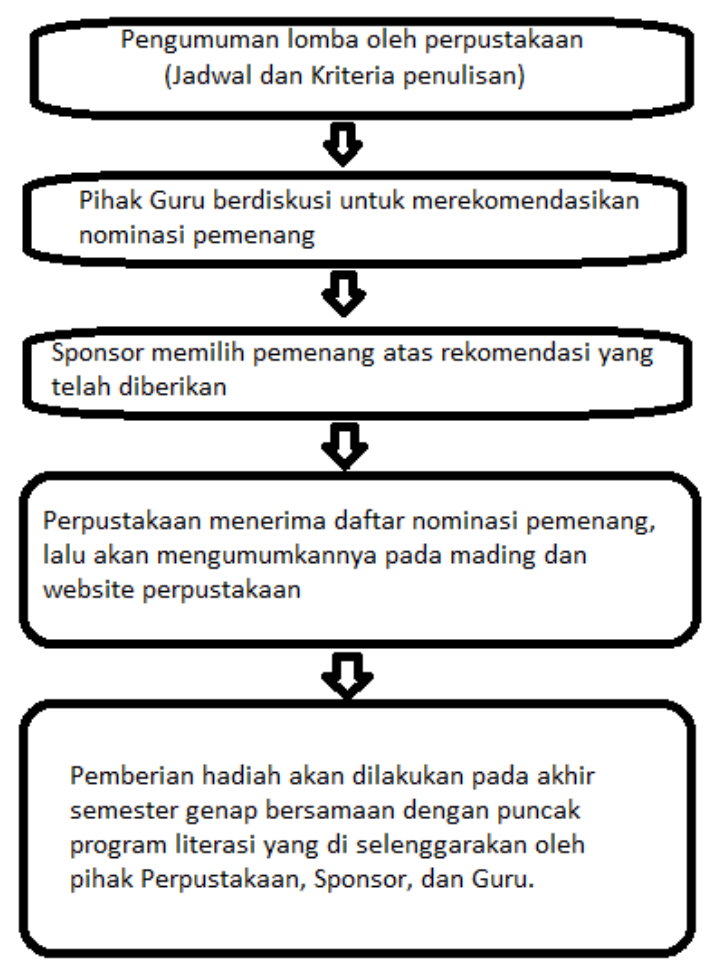

Gambar 4.

\section{c. Program Per Semester}

\section{User Education}

Program ini khusus bagi peserta didik baru dengan tujuan untuk memperkenalkan Perpustakaan. Dengan memahami Perpustakaan (letak, fasilitas, fungsifungsi, dan program literasi) diharapkan peserta didik mampu memanfaatkannya untuk meningkatkankemampuan berliterasinya. Program ini di adakan pada hari terakhir masa OSPEK atau pengenalan lingkungan sekolah.

\section{Reading and Writing Award.}

Penghargaan ini terkait dengan program literasi sebelumnya. Penilaian didasarkan pada Program literasi Harian \& Mingguan dari hasil rekapitulasi tiap minggunya oleh Perpustakaan. Proses pengumuman nominasi pemenang akan dilakukan seperti biasanya melalui mading dan website perpustakaan. Penyerahan piala dan hadiah akan dilakukan bersamaan dengan program Bulanan pada akhir semester genap.

\section{Duta Perpustakaan}

Sebagai sarana promosi perpustakaan, peneliti merancanakan sebuah program untuk pemilihan Duta Perpustakaan. Duta Perpustakaan dipilih oleh pihak Perpustakaan dengan mimilih siswa yang pernah menjadi pemenang program Teknik review. Duta perpustakaan terdiri atas beberapa siswa setiap angkatan kelas memiliki 2-4 anggota, yang masingmasing memiliki tugas :

1. Membantu pihak perpustakaan dalam kegiatan sirkulasi, pengolahan koleksi, dan layanan perpustakaan. 
2. Memotivasi teman-teman siswa lainnya untuk datang berkunjung ke perpustakaan.

Setiap Duta Perpustakaan mendapat tugas sekali dalam seminggu untuk menjalankan tugas diatas. Jam tugas bisa disesuaikan dengan jadwal siswa untuk memudahkan siswa dalam menjalankan tugasnya. Setiap siswa selesai menjalankan tugasnya mereka akan mendapatkan 1 poin. Poin yang terkumpul sejumlah 40 poin dapat ditukarkan voucher makan dan minum dikantin.

\section{Mengundang Tokoh untuk Sharing dan} Pelatihan

Untuk meningkatkan kemampuan berliterasi siswa, peneliti juga mencoba membuat program untuk mendatangkan beberapa penulis ataupun tokoh yang bisa memotivasi dan menularkan kemampuan literasinya kepada para siswa. Kegiatan ini dijadwalkan pada akhir dari Ujian Akhir Semester.

\section{PENSI (Pentas Literasi)}

Puncak dari seluruh Program literasi terletak pada program yang terakhir ini. Dalam program ini perpustakaan mencoba untuk membangun pentas yang berisi serangkaian lomba-lomba terkait literasi dan seni. Lomba-lomba tersebut meliputi: lomba membaca puisi, mendongeng, pidato, dan drama. Drama bisa diangkat dari best book selama periode tersebut atau sekelompok siswa dapat menentukannya sendiri namun dengan syarat melaporkannya pada Guru literasi ataupun pihak Perpustakaan. Pada program literasi terakhir ini akan dilangsungkan bersamaan dengan pemberian piala dan hadiah dari program-program Harian, Mingguan, dan Bulanan.

\section{Hambatan-hambatan}

Setiap tujuan pasti akan selalu ada sesuatu yang menghalanginya, begitupun untuk menjalankan program literasi Di Perpustakaan SMPN $X$ Kabupaten Banyuwangi. Sementara ini, fakta-fakta yang peneliti dapatkan dari beberapa hambatan-hambatan yang memungkinkan untuk menghalangi program ini antara lain

a) Kurangnya Sumber Informasi

Koleksi yang monoton atau koleksi yang itu-itu saja dapat melemahkan gairah siswa untuk membaca. Pilihan yang sedikit terkadang membuat siswa tidak tertarik lagi berkunjung di perpustakaan. Sehingga perpustakaan harus seimbang dalam menjalankan perannya sebagai penunjang pendidikan, baik deri segi pelayanan, sumber informasinya, fasilitas, dan program literasinya. 
b) Lingkungan

Kurangnya contoh baik disekitar siswa untuk memicu keinginan membacanya, akan membuat siswa merasa tidak ingin bahkan tidak perlu membaca. Apalagi di zaman sekarang para remaja usia menengah sudah lebih akrab bermain Handphone dari pada membaca buku.

c) Kebiasaan literasi kurang menjadi prioritas warga sekolah

Berbeda dengan negara maju yang menjadikan membaca sebagai kebutuhan primer, dinegara kita membaca masih menjadi sarana untuk memenuhi tugas dan kegiatan akademiknya saja. Masyarakat kita belum memnyadari betapa sangat pentingnya membaca sebagai pondasi masa depan.

\section{SIMPULAN}

Kondisi pendidikan ditingkat menengah yang menurun saat ini harus disikapi dengan serius, jika tidak secara pelan-pelan Indonesia akan terjajah kembali oleh kekuasaan negara lain. Remaja adalah usia-usia strategis sebagai penentu nasib bangsa ini kedepannya, maka dari itu Perpustakaan sebagai penunjang pendidikan di sekolah harus bisa berkontribusi dalam mengembangkan potensi berupa kepribadian, kecerdasan, ahlak mulia serta keterampilanketerampilan lainnya yang berguna untuk dirinya, masyrarakat, bangsa, dan negara.

Dengan pengadaan Program Literasi Perpustakaan diatas, diharapkan perpustakaan dapat benar-benar menjadi penunjang yang dapat mengasah kemampuan literasi para siswa Di SMPN $X$ Kabupaten Banyuwangi. Tentu program ini tidak dapat berjalan tanpa kerjasama antara pihak-pihak yang terkait, seperti pustakawan sebagai pelopor program ini, guru serta para staff, dan juga para wali murid. Hambatan selalu ada, untuk itu kita sebagai penggiat literasi harus meningkatkan kemampuan untuk menularkan literasi, tidak lagi sekedar berliterasi.

\section{DAFTAR PUSTAKA}

Departemen Pendidikan Nasional. (2003). Undang-Undang Nomor 20 Tahun 2003, Tentang Sistem Pendidikan Nasional. Jakarta: Departemen Pendidikan Nasional.

Koroh, Alexander B. (2015). "Belajarlah Dari Pengelolaan Perpustakaan Di Negara Maju - Pos Kupang." http://kupang.tribunnews.com/2015/0 2/12/belajarlah-dari-pengelolaanperpustakaan-di-negara-maju (December 1, 2018).

Napitupulu, Ester Lince. (2011). "Menguatkan Pendidikan Menengah Kompas.Com." 
https://edukasi.kompas.com/read/201 1/12/28/08301575/menguatkan.pendi dikan.menengah. (December 1, 2018).

Direktorat Jendral Pendidikan Dasar dan Menengah. Kementrian Pendidikan dan Kebudayaan. (2016). Panduan Gerakan Literasi Sekolah di Sekolah Menengah Pertama.
Setiyaningsih, Endang. "Gerakan Literasi Sekolah Melalui Program WJLRC Gerakan Literasi Sekolah." http://literasi.jabarprov.go.id/bacaartikel-452-gerakan-literasi-sekolahmelalui-program-wjlrc.html (December 1, 2018).

Sudarsono, Blasius. (2009). Pustakawan Cinta Dan Teknologi. Jakarta: Sagung Seto. 